\title{
Pedospheric adsorption-desorption of anti-moulting agent Chlorfluazuron and transfer in agriculturally significant Arcadian soils
}

\author{
SUNDUS AZHAR and KHURAM SHAHZAD AHMAD* \\ Department of Environmental Sciences, Fatima Jinnah Women University, The Mall, Rawalpindi 46000, \\ Pakistan \\ e-mail: chemist.phd33@yahoo.com; dr.k.s.ahmad@fjwu.edu.pk
}

MS received 29 August 2018; revised 29 May 2019; accepted 6 September 2019

\begin{abstract}
Agrochemical-based soil and water contamination has been posing serious threats to ecological balance. Current research investigates the sorption and mobility behaviour of a Benzylurea insecticide, Chlorfluazuron (CFZ), by a standard batch equilibrium method. After investigation of soils' physical and chemical properties, sorption assays have been performed on five soils from agriculturally significant regions where CFZ can probably occur. CFZ expressed poor adsorption on the selected soils with linear adsorption coefficient, i.e. $K_{\mathrm{d}(\mathrm{ads})}$, ranging between 6.08 and $9.57 \mu \mathrm{g} / \mathrm{mL}$ and Freundlich adsorption coefficient $K_{\mathrm{f}(\mathrm{ads})}$ having a range of 4.18-9.01 $\mu \mathrm{g} / \mathrm{mL}$. Linear and Freundlich models displayed correlation coefficient $R^{2}$ value to be $\geq 0.84$ and 0.83 , respectively, reflecting the goodness of fit of the experimental data. Furthermore, the mobility of CFZ was assessed using the McCall classification based on $K_{\mathrm{oc}}$ values. CFZ expressed high mobility in soils with less adsorption. The adsorptive and desorptive interactions were highly dependent upon soil physicochemical characteristics. Based on the current investigation, CFZ can be predicted to be a potential threat for soils with a low adsorptive affinity towards it. Future investigations in this regard can consider the use of sustainable materials and procedure for CFZ decontamination in vulnerable soils.
\end{abstract}

Keywords. Benzoylurea; insecticide; soil; batch equilibrium; organic matter; pedotransfer.

\section{Introduction}

Vicious agricultural pests have been controlled by means of different insecticides, which have been gaining an invasion into the food matrix. In this regard, the effects of these synthetic insecticides have been investigated on the target species behaviour [1]. There are some social insects present on a global scale that are involved in the natural process of degrading and recycling of organic components in the agricultural set-ups [2]. Such pests have increased resistivity and enhanced strength for their survival, which has resulted in the ever-increasing use of synthetic controlling agents in the form of pesticides. This trend corresponds to the global scale pesticide usage [3,4]. Such an increment, on one hand, is useful in controlling the pests attack, enhancing the agricultural productivity and putting an end to the deficiencies in food demand. On the other hand, there are increased risks of environmental contamination reflected by poor functioning of air, water and soil compartments, straying away from the normal functioning. Pesticides are known for causing a major portion of pollution in soils and

*For correspondence

Published online: 03 October 2019 groundwater bodies through leaching [5]. Insecticides have been known for their persistence and toxicity [6]. In this regard, efforts have also been made to synthesize insecticides and other pesticides in a way such that they exhibit less toxicity and ecological disruption. This is done either by using less persistent and high polarity components or by making the mode of action more selective [7]. There has been considerable concern about those substances that might not be harmful to the target species but they have commendable transportation towards the deeper soil profiles and consequent groundwater contamination due to polarity.

An important class of insecticides, known as N-benzoyl$\mathrm{N}^{\prime}$-phenyl ureas (BPUs), were introduced some six to seven decades ago for controlling the insect growth by acting as insect growth regulators (IGRs). BPUs have been categorized as the major preventers of chitin biosynthesis mechanism by a specific mode of action as revealed by Insecticide Resistance Action Committee (IRAC). These BPUs are specialized for controlling various pests, and can be used as acaricides and termiticides in addition to their use as ectoparasiticides for controlling the infectious animal diseases in veterinary purposes. BPUs are of significance 
for affecting the larval stage of pests that pose more harm towards the crops [7]. Chlorfluazuron (N-[[[3,5-dichloro-4[[3-chloro-5-(trifluoromethyl)-2-

pyridinyl]oxy]phenyl]amino]carbonyl]-2,6-difluorobenzamide, CFZ) is one of the members of the BPUs class of insecticides. CFZ is available in commercial markets with the trademarks of Abron for controlling the Lepidoptera feeding on the major agricultural crops, e.g. vegetables, fruits, cereals, etc. Furthermore, CFZ does not possess any kind of system activity in plants in systemic and translaminar aspect [8]. The purpose of its introduction was enhanced activity against the lepidopteron pests feeding on crops that are resistant towards insecticides. CFZ has been used rampantly because it has no impact on non-target organisms [9]. For this purpose, programs aimed at integrated pest management (IPM) have been making use of CFZ [10]. Investigations are suggestive of the half-life values for CFZ ranging between 6.03 and $8.10 \mathrm{~d}$ [11].

CFZ expressed more leaching towards soil profiles beyond those given by the United States Environmental Protection Agency (US EPA) [12]. Adsorption models provide different shape isotherms, which are indicative of the bonding between insecticide and soils. For most of the synthetic organic insecticides and many other categories of pesticides, models such as Henry, Freundlich and hyperbolic Langmuir give the best fit results [13]. Furthermore, insecticide mobility in different soil profiles is also reflected in such adsorptive interactions. Mobility has been shown to be enhanced in the presence of dissolved organic matter (DOM) [14-18].

The agricultural sector of Pakistan is highly dependent upon the use of synthetic pesticides, including insecticides. CFZ has been used for controlling different insects. However, no studies have been done on the adsorption-desorption and mobility pattern of CFZ in regions of Lahore, Rawalpindi, Jhelum, Gujrat and Attock. Thus, current work has been undertaken to investigate CFZ chemical attachment and detachment with the selected soils by means of a standard batch equilibrium process. Results of current work possess significance for soil scientists, agriculturalists, environmentalists and chemical engineers to comprehend the threats posed by CFZ in Pakistani soils and devise remedial measure.

\section{Experimental}

\subsection{Materials}

Analytical grade CFZ, anhydrous sodium chloride and calcium chloride were purchased from Sigma Aldrich, Germany, and used without further modifications. All experiments were performed by utilization of distilled water (DW). Prior to each experiment, the apparatus was rinsed with acetone and oven dried to prevent contamination.

\subsection{Soil sampling and preparative procedure}

Soil samples were collected through random sampling from five arcadian soils of Punjab province in Pakistan. Soil samples were obtained from Lahore $\left(31.5204^{\circ} \mathrm{N}\right.$, $\left.74.3587^{\circ} \mathrm{E}\right)$, Rawalpindi $\left(33.5651^{\circ} \mathrm{N}, 73.0169^{\circ} \mathrm{E}\right)$, Jhelum $\left(32.9425^{\circ} \mathrm{N}, 73.7257^{\circ} \mathrm{E}\right)$, Gujrat $\left(32.5731^{\circ} \mathrm{N}, 74.1005^{\circ} \mathrm{E}\right)$ and Attock $\left(33.7660^{\circ} \mathrm{N}, 72.3609^{\circ} \mathrm{E}\right)$. Samples were collected from a depth of $0-20 \mathrm{~cm}$ and were stored in wellsterilized polythene bags. Subsamples of the respective regions were mixed thoroughly in order to achieve homogeneity followed by air drying for $24 \mathrm{~h}$. Dried soil samples were later disaggregated manually using a mortar and pestle. Samples were passed through a sieve of size $2 \mathrm{~mm}$ in order to ensure the homogeneity of soil samples. The prepared soils were kept in well-sterilized polythene bags labelled with the name of respective regions.

\subsection{Soil physicochemical characterization}

Selected soils were characterized for different physical and chemical parameters, i.e. electrical conductivity (EC), $\mathrm{pH}$, organic matter (OM), available phosphorus, available potassium, cation exchange capacity (EC), total nitrogen, total organic content, texture and colour of the prepared soil samples.

2.3a Soil EC: A conductivity meter was used to determine the EC of the soil samples. Soil solution was prepared with DW by taking $1 \mathrm{~g}$ of the soil in a beaker and subsequently adding $10 \mathrm{~mL}$ of re-distilled water in the soil sample in order to make a paste-like material, which was left for $1 \mathrm{~h}$ to ensure the dissolution of salts present in the solution. The conductivity meter was then calibrated using a standard solution of $0.01 \mathrm{~N} \mathrm{KCl}$. After $1 \mathrm{~h}$, the temperature of the calibrated conductivity meter was adjusted at $25^{\circ} \mathrm{C}$ and the cell was dipped in the soil water suspension, making sure that there were no air bubbles. Final EC value of the solutions was then noted in $\mathrm{mS} \mathrm{cm}^{-1}$ or $\mathrm{dS} \mathrm{m} \mathrm{m}^{-1}$.

2.3b Soil $\mathrm{pH}: \mathrm{pH}$ is the measure of acidity or alkalinity of any aqueous solution measured using a $\mathrm{pH}$ meter (MM40+ Crimson Company). Soil-water solution was prepared in 1:10 ratio and left for $1 \mathrm{~h}$. The electrode of the $\mathrm{pH}$ meter was dipped in the soil solution and $\mathrm{pH}$ was noted down. For each soil sample, electrode of the $\mathrm{pH}$ meter was washed with DW, dried with a cotton cloth and was calibrated using standard buffer solutions of $\mathrm{pH} 4.01,7.0$ and 9.21 in order to avoid any inconvenience in results due to systematic error. $\mathrm{pH}$ was measured thrice, followed by taking its average.

2.3c Soil organic matter: Loss by ignition method was used to determine organic matter content $(\% \mathrm{OM})$ of soil samples. A 5-g soil sample was kept in a hot air dryer oven at $105^{\circ} \mathrm{C}$ for $24 \mathrm{~h}$. After $24 \mathrm{~h}$, soil samples were weighted 
again and placed in crucibles, which were then kept in a muffle furnace at $375^{\circ} \mathrm{C}$ for $1 \mathrm{~h}$. After ignition, soil samples were weighted again and \% $\mathrm{OM}$ was calculated by the following formula:

$\% \mathrm{OM}=$

$\frac{\text { pre - ignition weight }(g) \text { - post - ignition weight }(g)}{\text { pre }- \text { ignition weight }(g)} \times 100$.

2.3d Available phosphorus (P): Available phosphorus was calculated by adding $50 \mathrm{~mL}$ of extracting solution in $2.5 \mathrm{~g}$ of prepared soil. The solution was shaken for $30 \mathrm{~min}$ to obtain homogeneity, which was later filtered using Whatman No. 42 filter paper; $5 \mathrm{~mL}$ aliquot of this solution was added in $25 \mathrm{~mL}$ volumetric flask along with $5 \mathrm{~mL}$ of colour developing agent. The solution was shaken well to remove water bubbles. The volume of the solution in the volumetric flask was raised up to $25 \mathrm{~mL}$ by adding stock solution. As soon as the stock solution was added in the volumetric flask, colour of the solution transformed to bluish. The intensity of colour was directly proportional to amount of phosphorus in the solution and was subjected to analysis using a UV-visible spectrophotometer (BMS 1602) at $880 \mathrm{~nm}$ wavelength.

2.3e Available potassium (K) In all, $2.5 \mathrm{~g}$ of prepared soil was added in a $250 \mathrm{~mL}$ conical flask; $50 \mathrm{~mL}$ of extracting solution was also added and the whole solution was shaken well for $30 \mathrm{~min}$ using a flatbed reciprocal shaker. The extract was then filtered using Whatman No. 42 filter paper and the amount of available $\mathrm{K}$ in soil samples was determined using a flame photometer using graph readings.

2.3f Cation exchange capacity: Cation exchange capacity (CEC) of the selected soils was calculated by adding $33 \mathrm{~mL}$ of reagent $\mathrm{A}$ ( $1 \mathrm{~N}$ Sodium acetate) in $5 \mathrm{~g}$ soil and shaken for 10 min followed by centrifugation at $1200-2000 \mathrm{rpm}$ for 5 min. Reagent A was added twice while reagent B $(95 \%$ ethanol) was added once and the same procedure of shaking and centrifugation was followed. The same procedure was repeated using reagent $\mathrm{B}$ twice. Reagent $\mathrm{C}$ was prepared by dissolving $77.08 \mathrm{~g}$ ammonium acetate into DW. The volume was then raised up to the mark in the flask. Ammonium hydroxide was used to maintain the $\mathrm{pH}$ up to 7 . The reaction mixture was added with reagent $\mathrm{C}$ and the same procedure was repeated again. In the final step, the volume was raised up to $100 \mathrm{~mL}$ with DW. The solution was then taken to a flame photometer in order to determine replaced $\mathrm{Na}$.

2.3g Total nitrogen $(N)$ : Total nitrogen of the soil samples was calculated using the following formula:

$$
\text { Total nitrogen }=\mathrm{OM}(\%)-0.05 \text {. }
$$

2.3h Total organic carbon: Total organic carbon (TOC) of the soil samples was calculated using following formula:

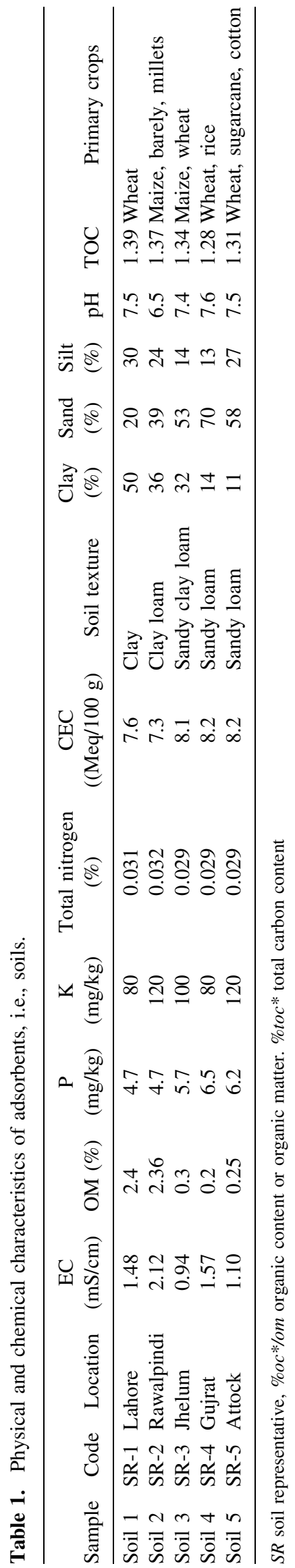


Table 2. Linear and Freundlich parameters of Chlorfluazuron adsorption in the selected soils.

\begin{tabular}{llcccccccccccc}
\hline Soil & Region & $K_{\mathrm{d}}(\mu \mathrm{g} / \mathrm{mL})$ & $R^{2}$ & $K_{\mathrm{oc}}$ & $S$ & $K_{\mathrm{f}}(\mu \mathrm{g} / \mathrm{mL})$ & $1 / n$ & $n_{\mathrm{a}}$ & $R^{2}$ & $S$ & $K_{\text {foc }}$ & $K_{\mathrm{OM}}$ & $\Delta G(\mathrm{~kJ} / \mathrm{mol})$ \\
\hline SR-1 & Lahore & 77.92 & 0.85 & 576 & 2.24 & 7.35 & $1 / 0.59$ & 1.70 & 0.83 & 0.13 & 299 & 174 & -12.79 \\
SR-2 & Rawalpindi & 9.57 & 0.98 & 697 & 2.08 & 9.01 & $1 / 0.82$ & 1.22 & 0.96 & 0.09 & 656 & 381 & -14.7 \\
SR-3 & Jhelum & 6.08 & 0.90 & 454 & 1.14 & 4.72 & $1 / 0.40$ & 2.46 & 0.90 & 0.08 & 353 & 205 & -13.2 \\
SR-4 & Gujrat & 8.04 & 0.84 & 619 & 0.38 & 4.18 & $1 / 0.14$ & 7.09 & 0.92 & 0.03 & 574 & 334 & -14.4 \\
SR-5 & Attock & 6.87 & 0.88 & 525 & 2.03 & 6.05 & $1 / 0.49$ & 2.01 & 0.98 & 0.05 & 462 & 268 & -13.9 \\
\hline
\end{tabular}
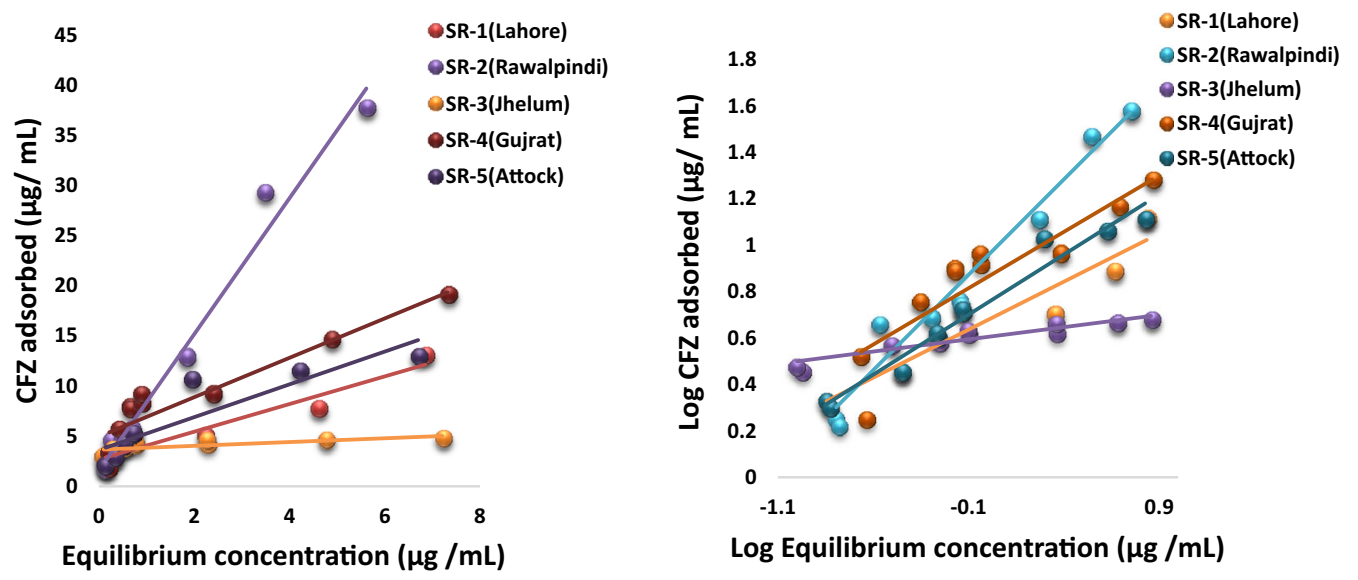

Figure 1. Comparative linear and Freundlich adsorption of Chlorfluazuron.

$$
\mathrm{TOC}=\mathrm{OM}(\%) / 1.72
$$

2.3i Soil texture: Soils were sieved for texture determination using an Octagon digital sieve shaker by taking $100 \mathrm{~g}$ of soil in the shaker for $1 \mathrm{~h}$. Selected soils were separated between four different sieves having sizes from 425 to $38 \mathrm{~mm}$. Soil texture was determined by weighing the amount of soil in respective sieves.

\subsection{Batch equilibrium method}

CFZ adsorption-desorption in soils was performed by standard batch equilibrium method following the OECD Guidelines for the Testing of Chemicals [19]. Sorption experiments were performed at room temperature of $25 \pm 1{ }^{\circ} \mathrm{C}$. All experimentations were performed in triplicates. CFZ stock solution was arranged by dissolving $10.3 \mathrm{mg}$ of CFZ in $1000 \mathrm{~mL}$ of DW followed by magnetic stirring for $24 \mathrm{~h}$. Discrete CFZ dilutions were prepared including $0.25,0.5,0.75,1.0,2.5,5.0$ and $7.5 \mathrm{ppm} ; 10 \mathrm{~mL}$ of $0.1 \mathrm{M} \mathrm{NaCl}$ was added to each dilution in a centrifuge tube. $\mathrm{NaCl}$ facilitated the stimulation of ionic strength of solution by impersonating as a background electrolyte mimicking the ionic phase in the natural pedosphere; $0.5 \mathrm{~g}$ of the selected soils was also added in the respective tubes.
Subsequently the tubes were placed in a Stuart Orbital Shaker at room temperature for $24 \mathrm{~h}$ at $150 \mathrm{rpm}$ for the establishment of the equilibrium. Furthermore, a blank soilless sample containing only dissolved $\mathrm{CFZ}$ and $0.1 \mathrm{M} \mathrm{NaCl}$ was treated in parallel with each set of a batch experiment in order to quantitate the losses and to rationalize possible degradation during the adsorption process. The centrifuge tubes containing equilibrated material were then centrifuged at $3000 \mathrm{rpm}$ for $25 \mathrm{~min}$ at $25^{\circ} \mathrm{C}$. The centrifuged tubes were decanted by filtering soil water suspension through a $0.2 \mu \mathrm{m}$ Nucleopore nylon membrane and clear aliquots were taken for the analysis of CFZ via the UVvisible spectrophotometer. Following the adsorption process, CFZ desorption concentration was examined. The supernatant was decanted and the same batch was poured with $9 \mathrm{~mL}$ freshly prepared $0.01 \mathrm{M} \mathrm{CaCl} 2$ solution. A similar procedure was followed for desorption encompassing shaking and centrifugation with subsequent analysis by UV-visible. Linear and Freundlich adsorption and desorption models were applied to the experimental values to obtain various isotherms [20-22].

The adsorbed and desorbed concentration of CFZ $(\mu \mathrm{g} / \mathrm{mL})$ on soil was determined by various linear and Freundlich equations as previously mentioned in various research works [20-22]. 

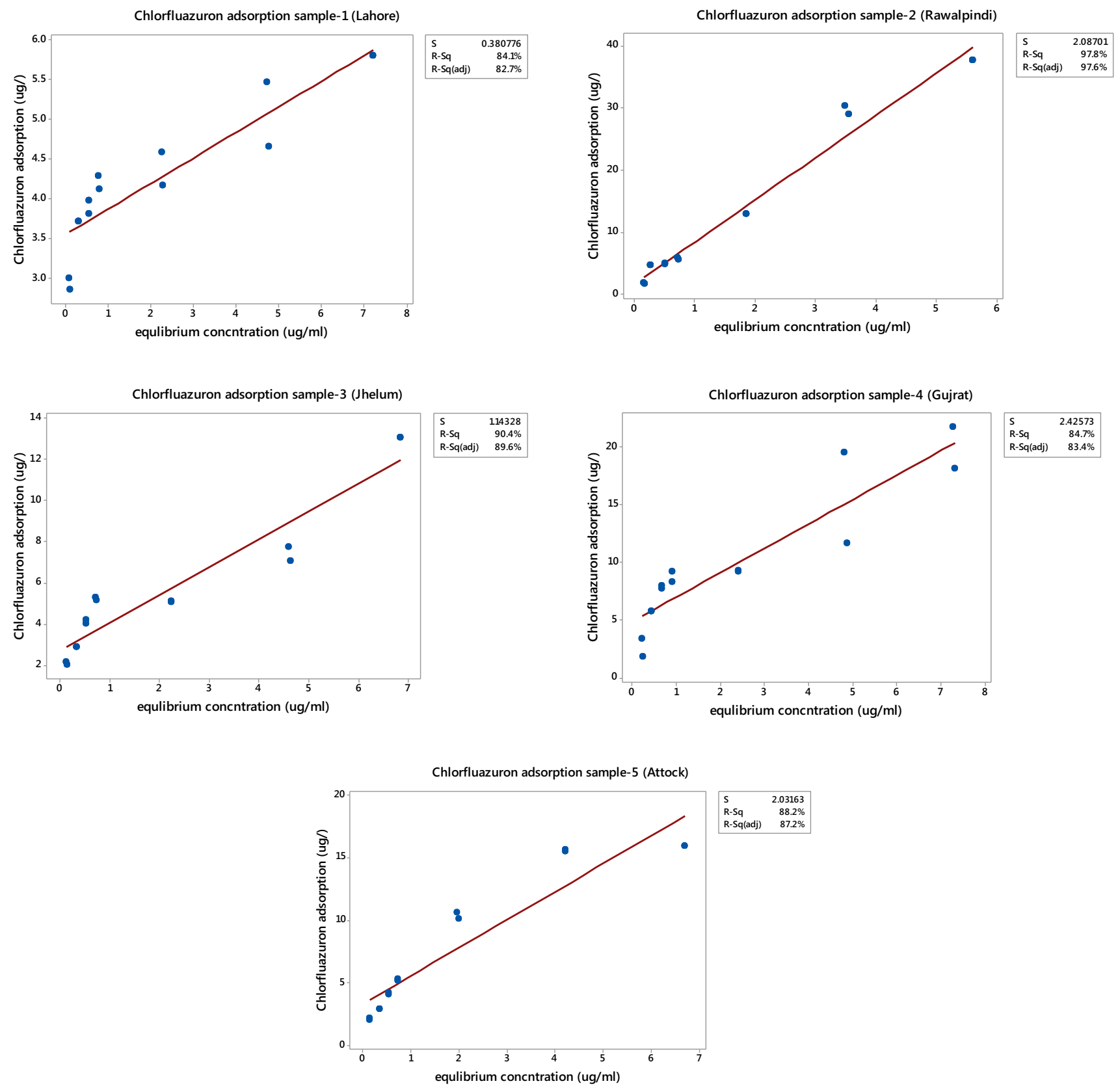

Figure 2. Minitab linear isotherms of Chlorfluazuron adsorption.

\section{Results and discussion}

Xenobiotic contamination is one of the major hitches of using synthetic organic chemicals in the agricultural domain. Research works have also been suggestive of the fact that once pesticides are released into the natural environments, there is a myriad of factors that facilitate the transportation of insecticides to lower profiles and groundwater reservoir [20]. Current investigations performed by standard batch equilibrium process with five selected soils are indicative of the sorption and mobility of the CFZ and show the dependence on the soils' physicochemical parameters [21-23].

\subsection{Physicochemical characterization}

Soils selected from different regions of Pakistan with no previous history of pesticide application have shown a difference in their physical and chemical characteristics. Such difference can be attributed to a variety of factors, inclusive of these regions' climatic pattern, precipitation, parent rock 

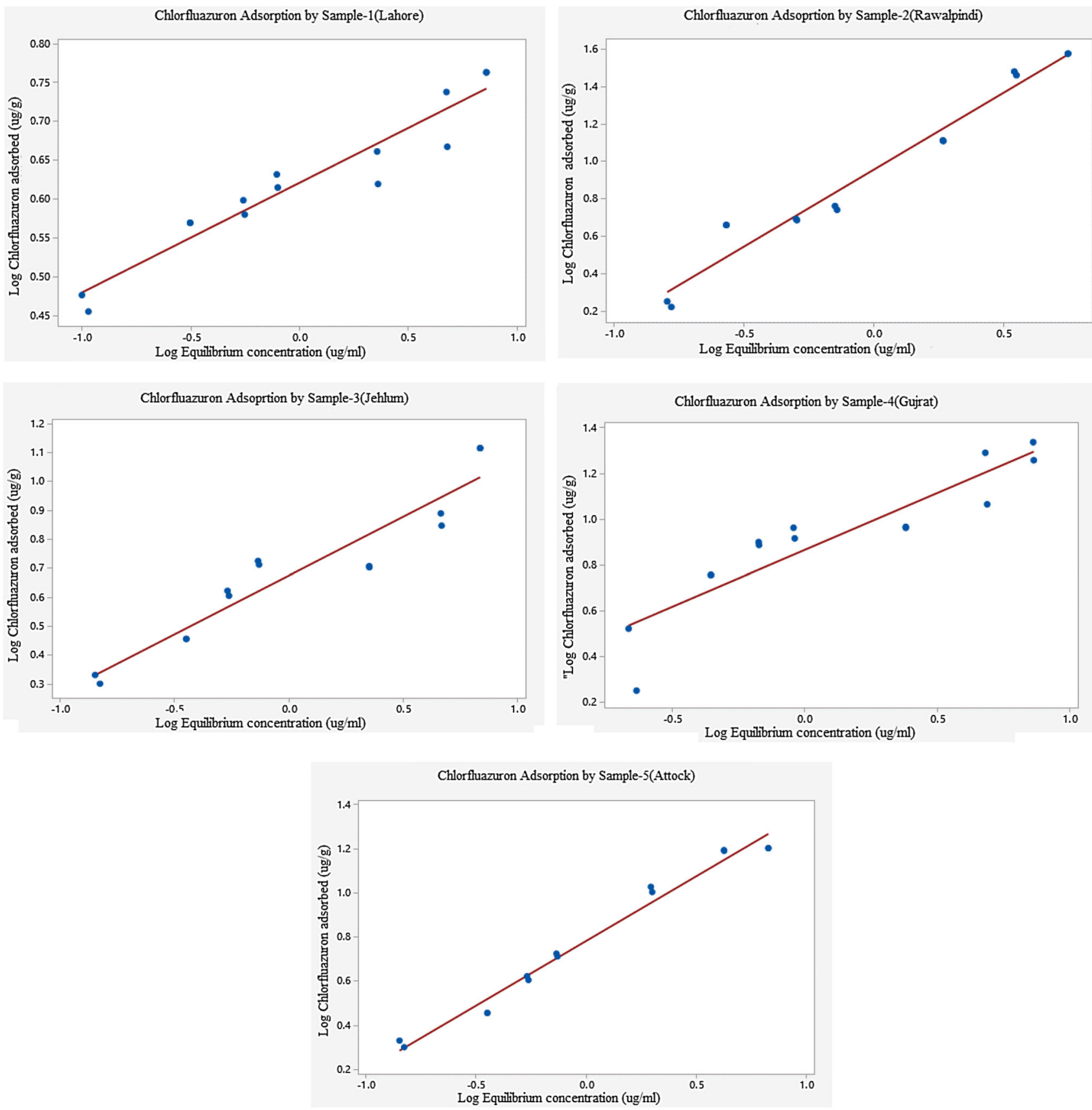

Figure 3. Minitab Freundlich isotherms of Chlorfluazuron adsorption.

Table 3. Linear and Freundlich parameters of Chlorfluazuron desorption in the selected soils.

\begin{tabular}{llcrrrrrrrr}
\hline Soil & Region & $K_{\mathrm{d}(\mathrm{des})}(\mu \mathrm{g} / \mathrm{mL})$ & $R^{2}$ & $S$ & $K_{\mathrm{f}(\mathrm{des})}(\mu \mathrm{g} / \mathrm{mL})$ & $1 / n$ & $\mathrm{Nd}$ & $R^{2}$ & $S$ \\
\hline SR-1 & Lahore & 6.57 & 0.99 & 0.58 & 1.24 & $1 / 0.96$ & 1.04 & 0.98 & 0.10 & 0.86 \\
SR-2 & Rawalpindi & 4.05 & 0.95 & 1.36 & 3.91 & $1 / 0.46$ & 2.17 & 0.92 & 0.12 & 1.28 \\
SR-3 & Jhelum & 8.72 & 0.93 & 0.48 & 3.77 & $1 / 1.44$ & 0.69 & 0.89 & 0.09 & 0.28 \\
SR-4 & Gujrat & 4.12 & 0.80 & 0.64 & 6.69 & $1 / 0.83$ & 1.21 & 0.87 & 0.23 & 0.60 \\
SR-5 & Attock & 5.35 & 0.99 & 0.22 & 4.12 & $1 / 0.89$ & 1.12 & 0.95 & 0.14 & 0.55 \\
\hline
\end{tabular}



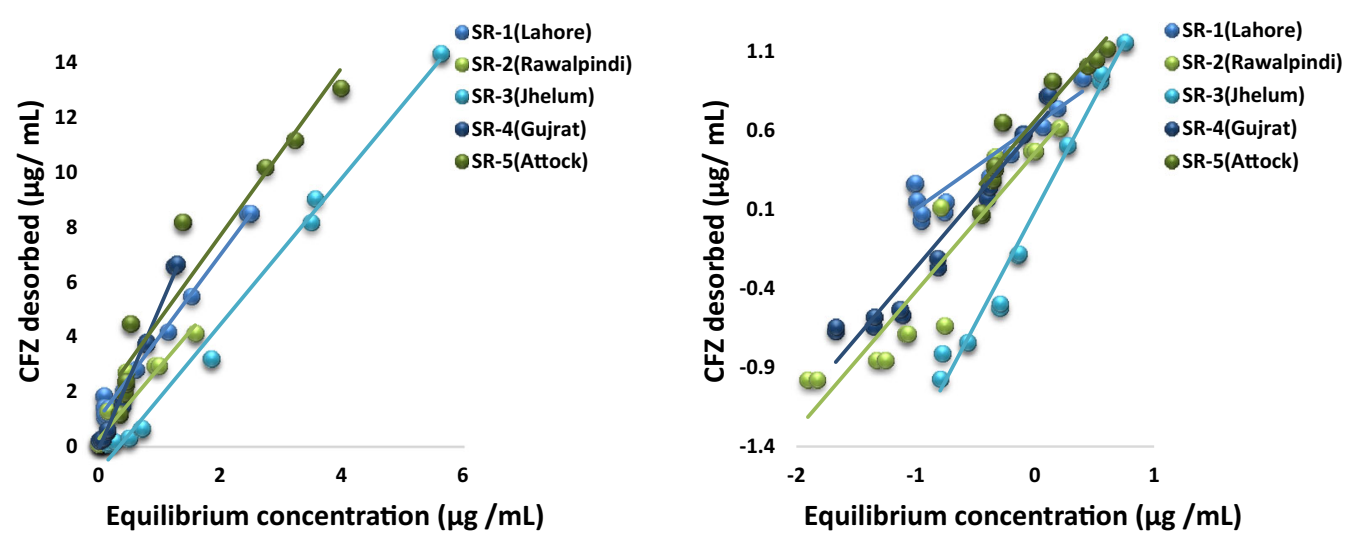

Figure 4. Comparative linear and Freundlich desorption of Chlorfluazuron.

material, nutrient recycling, etc. The soils varied in their respective $\mathrm{EC}$ (table 1). The $\mathrm{EC}$ of the soil is the measure of the total ionic content of those soils. EC thus gives the number of soluble salts in the soil. Any soil having higher EC will possibly be providing more attractive forces for binding with the organic contaminates and heavy metals. In the current investigation, the highest EC was exhibited by SR-2 taken from Rawalpindi region $\left(2.12 \mathrm{mS} \mathrm{cm}^{-1}\right)$. EC also influences the OM deposition in an area by developing different types of bonds with the functional groups of decaying substances. $\mathrm{pH}$ ranges obtained in the current investigation have shown the soils to be in the neutral range except for SR-2 taken from Rawalpindi region, which possessed a slight acidic $\mathrm{pH}$ (6.25). Current results are in concordance with the previous research works on Punjab's soils in having neutral $\mathrm{pH}$ ranges $[24,25]$. The OM content of soils displays its ability for greater binding of pesticides molecules to soil particles. The OM in the current collection of tested samples ranged from $0.94 \%$ to $2.12 \%$. Sample SR1 expressed higher OM percentage of $2.4 \%$. The lowest OM was observed in SR-3 while the highest was in SR-2. Another decisive factor for various mechanisms is soil sand percentage. Sand content in the present research varied from $20 \%$ to $70 \%$. The highest sand content was present in SR-4 $(70 \%)$. A greater sand content impedes the binding of molecules to soil particles, thus promulgating itself as an imperative component of soil physicochemical properties. The lowest amount of sand was observed in SR-1 (20\%), indicating the fact that this soil might display better binding with various molecules. Furthermore, the soils with a high OM content have been observed to possess low sand percentage, as depicted by SR-1.

\subsection{Adsorption variation with soils physicochemical parameters}

Sorption experiments were performed on SR-1-SR-5 to understand the effects of soils' physicochemical parameters on the adsorption of CFZ. For this purpose, two multilayer adsorption models, i.e., linear and Freundlich, were applied for comprehending CFZ attachment and detachment with SR-1-SR-5 in the lab-based experiments. Different parameters found for both models have been tabulated in table 2. Obtained model data was then plotted in the form of comparative graphs on Microsoft Excel (2013) by taking equilibrium concentration $(\mu \mathrm{g} / \mathrm{mL})$ on $X$-axis and CFZ adsorbed $(\mu \mathrm{g} / \mathrm{mL})$ on $Y$-axis (figure 1$)$. For the Freundlich model, the $\log$ of this data was taken and plotted in the same manner on $X$ - and $Y$-axis. The isotherms were drawn using Minitab software (figures 2 and 3).

Research works have supported the impact of binding forces on pesticide adsorption. Some of the results have also pointed out that there could be chances for pesticides possessing negligible water solubility but an elevated octanol-water partition coefficient $\left(P_{\text {ow }}\right)$ and consequently such pesticides showed stronger adsorption with soils [26].

In the present investigation, the linear adsorption coefficient $K_{\mathrm{d}(\mathrm{ads})}$ ranged from 6.08 to $9.57 \mu \mathrm{g} / \mathrm{mL}$ in the selected soils exhibiting attachment of CFZ to the selected soils. However, among all soils, SR-2 obtained from Rawalpindi region expressed the highest value of $9.57 \mu \mathrm{g} /$ $\mathrm{mL}$ followed by SR-4 with $K_{\mathrm{d}(\text { ads })}$ having $8.04 \mu \mathrm{g} / \mathrm{mL}$.

The overall $K_{\mathrm{d}(\text { ads })}$ trend observed was SR-2 $>$ SR$4>$ SR-1 $>$ SR-3 $>$ SR-5. $K_{\text {om }}$ represents the adsorption coefficient of CFZ normalized on OM. $K_{\text {om }}$ ranged from 174.3 to $381.7 \mu \mathrm{g} / \mathrm{mL}$. SR-2 exhibited the highest $K_{\mathrm{om}}$ value since it also displayed the highest $K_{\mathrm{d}(\mathrm{ads})} \cdot R^{2}$ for linear adsorption ranged from 0.85 to 0.98 . The $R^{2}$ value displays the best fit of the experimental results to linear adsorption model.

The experimental values were also subjected to Freundlich sorption model for adsorption and desorption evaluation of CFZ in the soil tests. The Freundlich adsorption distribution coefficient values ranged from 4.18 to $9.01 \mu \mathrm{g} / \mathrm{mL}$. The $K_{\mathrm{f}}$ values are in consonance with the $K_{\mathrm{d}}$ values obtained from the calculations. The value of $K_{\mathrm{foc}}$ depends upon the value of organic carbon (OC) present in 

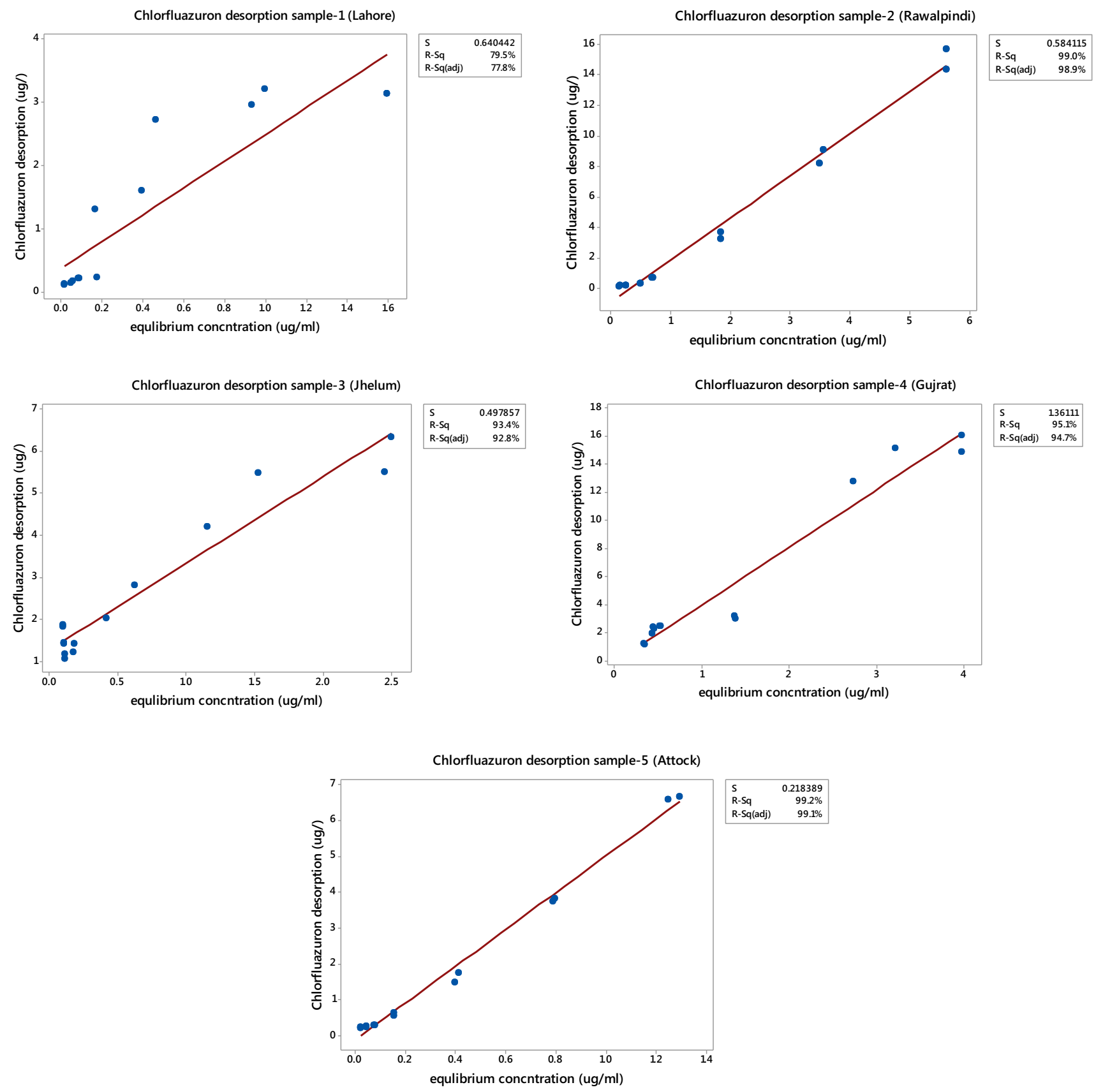

Figure 5. Minitab linear isotherms of Chlorfluazuron desorption.

the soil. Freundlich adsorption coefficient is also in conformity with $K_{\mathrm{d}(\mathrm{ads})}$.

The rate and extent of adsorption in soils are greatly dependent on and influenced by the soils' properties. The highest $K_{\mathrm{d}(\text { ads })}$ for SR-2 can be attributed to the highest EC, good OM and low $\mathrm{pH}$ encouraging the larger survival of microbial fauna, which can convert the dead organisms into soil OM. OM is a significant factor affecting the adsorption. The CFZ-OM complex formed in soils acts as a providence of abundant functional groups in the form of active sites to the CFZ molecules. There is a general agreement on the influence of the OM on pesticide adsorption in soils [15, 27-29]. Nevertheless, the complete mechanism justifying the domineering role of $\mathrm{OM}$ in attracting the CFZ molecules and not leaching them downwards needs to be investigated using advanced approaches and technological aid [30]. Research works investigating the adsorption of different insecticides have stressed upon the exploration of a large number of samples so that a meaningful conclusion can be arrived regarding insecticide-soil adsorption [31]. 

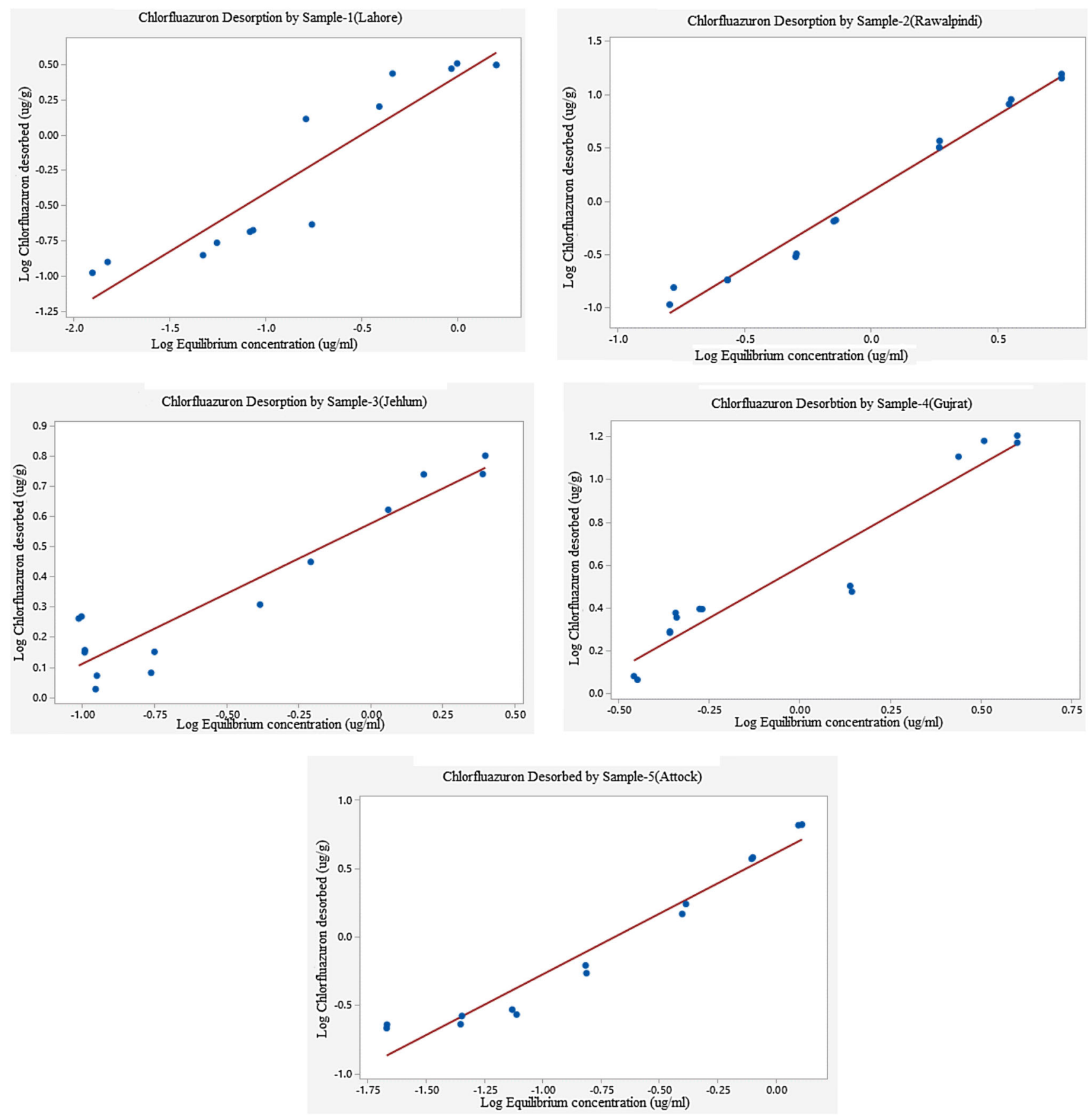

Figure 6. Minitab Freundlich isotherms of Chlorfluazuron desorption.

Current results are in conformity with the latest similar studies that have evaluated a number of pesticides based on the soils' physicochemical characteristics [32-36].

The present investigation shows that the value of Gibbs free energy $(\Delta G)$ is in the range of -12.79 to $-14.7 \mathrm{~kJ} / \mathrm{mol}$, pointing towards the fact that, consistent with previous scientific results, CFZ is physically adsorbed in all selected soil samples through weaker interactions, e.g. van der Waal's forces. These weak interactions are further reflected from lower $K_{\mathrm{d}(\mathrm{ads})}$ and $K_{\mathrm{f}(\mathrm{ads})}$ values.
Furthermore, $\Delta G \leq-40 \mathrm{~kJ} / \mathrm{mol}$ also indicates the reaction to be spontaneous and exothermic.

\subsection{CFZ migratory behaviour}

Current research also aimed at the exploration of pedotransfer of CFZ in the soil matrix reaching the groundwater reservoirs. In the present era, when humanity is in need of pure and fresh water, the pressure on the underground water 


\section{Residual Plots for Kd}
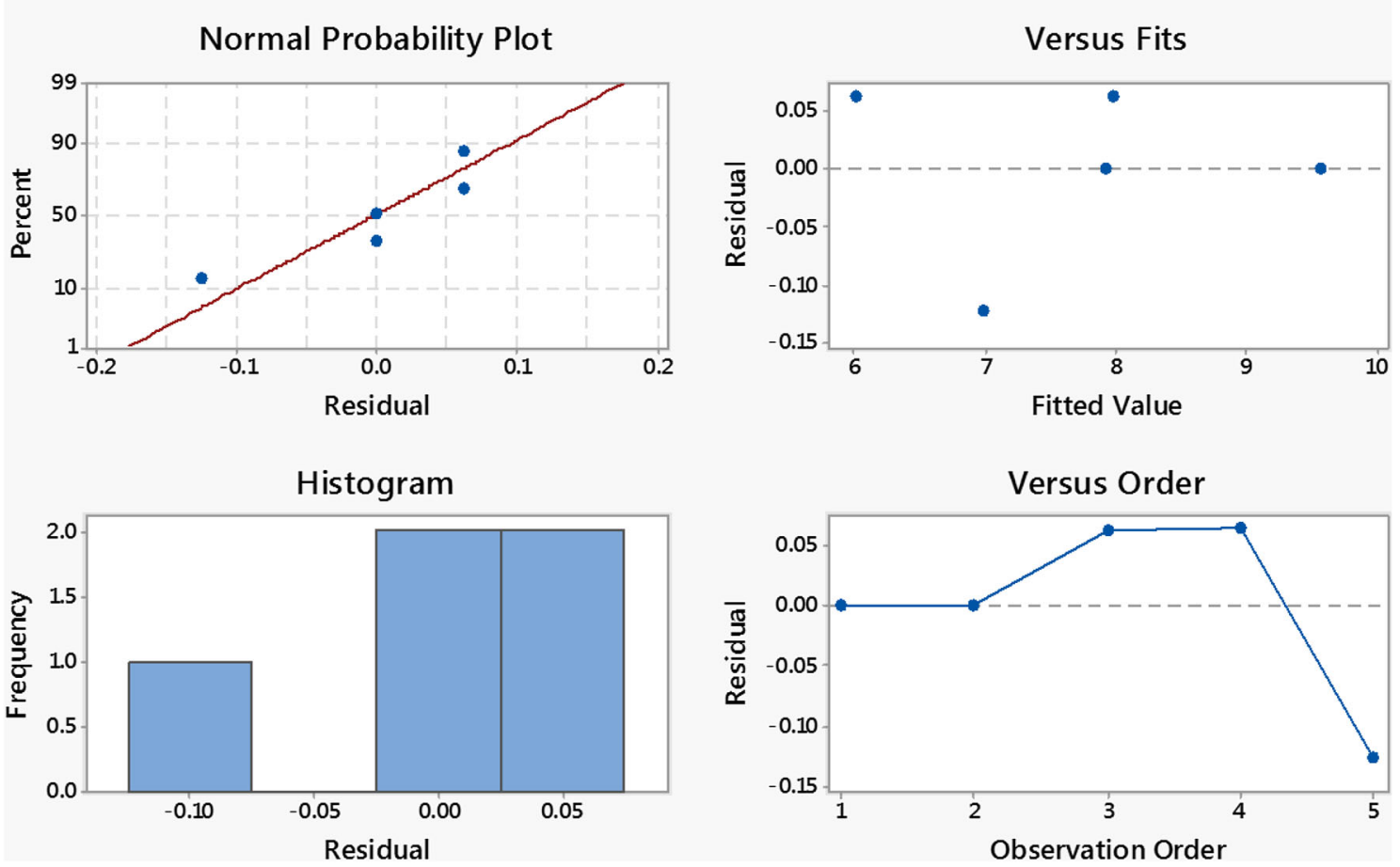

Figure 7. Analysis of variance (ANOVA) for soil physicochemical properties and adsorption distribution coefficient $K_{\mathrm{d}}$.

reserves has been elevated. Water harvesting from such sources will render the same health issues as the surface water contaminated with organic pollutants do [37, 38]. Nevertheless, such practice also affects soil inherent properties [39-41]. The mobility of CFZ was assessed via the McCall classification (1980) based on $K_{\mathrm{oc}}$ values. The sorption capacity of the soil is directly proportional to the $K_{\mathrm{oc}}$ value of the soils. CFZ expressed high mobility in soils with low adsorption and low mobility for soil samples from Rawalpindi and Gujrat $\left(K_{\mathrm{oc}}=697.5\right.$ and $619.1 \mu \mathrm{g} / \mathrm{mL}$, respectively). Studies on other pesticides have also expressed that soils showing poor adsorption potential are at the risk of contamination [20, 42].

\subsection{CFZ desorption}

CFZ desorption was also studied by UV-visible spectrophotometry. Soil samples with higher adsorption coefficients, i.e., SR-2 and SR-4, expressed lower desorption (4.05 and $4.12 \mu \mathrm{g} / \mathrm{mL}$ ) (table 3, figures 4, 5 and 6). These samples develop strong adsorptive interaction with CFZ, due to which they were not desorbed readily. Furthermore, SR-4 also possessed highest $\mathrm{pH}$ among all samples (7.6), thus displaying the least adsorption and highest rate of desorption. A high $\mathrm{pH}$ of soil obstructs and discourages the attachment of pesticide molecules to soil moiety. However, the other three soil samples expressed lower adsorption values for CFZ. In the present study, desorption hysteresis coefficient, $H$, in all five soils is found to be in the range of $0.28-1.28$. Value of $H$ close to 1 implies that the desorption process takes place as quickly as sorption does. The relatively high value of $K_{\mathrm{d}(\mathrm{ads})}$ compared with $K_{\mathrm{d}}$ (des) for studied soils shows that adsorption is irreversible.

\subsection{Statistical evaluation}

Soil physicochemical properties such as $\mathrm{pH}, \mathrm{OM}$ and TOC were subjected to statistical evaluation in relation to its adsorptive nature $\left(K_{\mathrm{d}}\right)$. All statistical tests were performed using Minitab statistical software 17. The dependence of CFZ adsorption on the soil properties was assessed by applying the general linear model for the analysis of variance (ANOVA), which displayed various residual graphs (figure 7). The residual plots obtained determined the goodness of fit of the experimental results.

\section{Conclusion}

This investigation revealed that CFZ displayed low binding capability in different agricultural soils. The adsorption and desorption of CFZ in soils followed the linear and Freundlich isotherms well and depended significantly on the 
properties of soils. The adsorption behaviour of CFZ was largely dependent upon soil $\mathrm{pH}$ value, $\mathrm{OC}$, clay content and OM. The extent of adsorption increased as $\mathrm{pH}$ value decreased, while the extent of adsorption increased as OC, clay content and OM increased. In this study, the desorption hysteresis of CFZ decreased from low to high solution concentrations and correlated significantly with the content of OM, OC and clay, suggesting that both solute concentration gradient and physicochemical properties of soil commonly controlled the adsorption-desorption behaviour of this herbicide. This study can set the future course of action of different studies on pesticides in soils and groundwater in Pakistan.

\section{Acknowledgements}

The authors acknowledge Fatimah Jinnah Women University, Rawalpindi, and Higher Education Commission of Pakistan for financial support.

\section{References}

[1] Evans T A and Iqbal N 2015 Termite (order Blattodea, infraorder Isoptera) baiting 20 years after commercial release. Pest Manag. Sci. 71(7): 897-906

[2] Carbo L, Martins E L, Dores E F, Spadotto C A, Weber O L and De-Lamonica-Freire E M 2007 Acetamiprid, carbendazim, diuron and thiamethoxam sorption in two Brazilian tropical soils. J. Environ. Sci. Health Part B 42(5): 499-507

[3] Zhang W, Jiang F and Ou J 2011 Global pesticide consumption and pollution: with China as a focus. Proc. Int. Acad. Ecol. Environ. Sci. 1(2): 125

[4] Mostafalou S and Abdollahi M 2013 Pesticides and human chronic diseases: evidences, mechanisms, and perspectives. Toxicol. Appl. Pharmacol. 268(2): 157-177

[5] UNEP 2004 Stockholm convention on persistent organic pollutants. United Nation Environment Programme, available from http://chm.pops.int/TheConvention/ThePOPs/Lis tingofPOPs (accessed July 2017)

[6] Unsworth J 2010 History of pesticide use. International Union of Pure and Applied Chemistry (IUPAC), available from http://agrochemicals.iupac.org/index.php?optioncom sobi2Details\&catid-3\&sobi2Id-31 (accessed July 2017)

[7] Ghimire N and Woodward R T 2013 Under- and over-use of pesticides: an international analysis. Ecol. Econ. 89: 73-81

[8] Farzana P 2012 Chlorfluazuron as reproductive inhibitor. In: Farzana P (Ed.) Insecticides-Pest Engineering. Rijeka, Croatia: InTech, pp. 23-62. ISBN 978-953-307-895-3

[9] Huo J C, Sun Y, Xu Y M, Qin X, Dai X H and Wei D 2010 Residue detection and degradation of chlorfluazuron in rice, soil and field water. J. Saf. Environ. 6: 004

[10] Chakraborty A and Sun B 2014 An adsorption isotherm equation for multi-types adsorption with thermodynamic correctness. Appl. Therm. Eng. 72(2): 190-199

[11] Ganguly P, Barik S R, Patra S, Roy S and Bhattacharyya A 2017 Persistence of chlorfluazuron in cabbage under different agro-climatic conditions of India and its risk assessment. Environ. Toxicol. Chem. https://doi.org/10. 1002/etc. 3872

[12] Radolinski J, Wu J, Xia K and Stewart R 2018 Transport of a neonicotinoid pesticide, thiamethoxam, from artificial seed coatings. Sci. Total Environ. 618: 561-568

[13] Leyva-Ramos R 2010 Fundamentos de adsorción en sistemas liquido-sólido. Situacion del arsenico en la Region Iberica e Iberoamericana. Posibles acciones articuladas e integradas para el abatimiento del arsenico en zonas aisladas. Argentina: CYTED, p. 43

[14] Chefetz B, Mualem T and Ben-Ari J 2008 Sorption and mobility of pharmaceutical compounds in soil irrigated with reclaimed wastewater. Chemosphere 73: 1335-1343

[15] Rodríguez-Liébana J A, Mingorance M D and Peña A 2013 Pesticide sorption on two contrasting mining soils by addition of organic wastes: effect of organic matter composition and soil solution properties. Colloids Surf. A Physicochem. Eng. Asp. 435: 71-77

[16] [16] Rodríguez-Liébana J A, Mingorance M D and Peña A 2011 Sorption of hydrophobic pesticides on a Mediterranean soil affected by wastewater, dissolved organic matter and salts. J. Environ. Manag. 92: 650-654

[17] ElGouzi S, Mingorance M D, Draoui K, Chtoun E H and Peña A 2012 Assessment of phenylurea herbicides sorption on various Mediterranean soils affected by irrigation with wastewater. Chemosphere 89: 334-339

[18] Borgman O and Chefetz B 2013 Combined effects of biosolids application and irrigation with reclaimed wastewater on transport of pharmaceutical compounds in arable soils. Water Res. 47: 3431-3443

[19] No O T 2000 Adsorption-desorption using a batch equilibrium method. OECD Guidelines for the Testing of Chemicals 106, pp. 1-45

[20] Alfonso L F, Germán G V, del Carmen P C M and Hossein G 2017 Adsorption of organophosphorus pesticides in tropical soils: the case of karst landscape of northwestern Yucatan. Chemosphere 166: 292-299

[21] Ahmad K S, Rashid N and Zakaria M 2015 Adsorption and desorption characteristic of metsulfuron-methyl in Pakistani soils. J. Chem. Soc. Pak. 37(2): 380-389

[22] Ahmad K S, Rashid N, Nazar M F and Tazaiyen S 2013 Adsorption and desorption characteristic of benzimidazole based fungicide carbendazim in Pakistani soils. J. Chem. Soc. Pak. 34(3): 1017-1024

[23] Ahmad K S, Rashid N, Tazaiyen S and Zakria M 2014 Sorption-desorption characteristics of benzimidazole based fungicide 2-(4-fluorophenyl)-1h-benzimidazole on physicochemical properties of selected Pakistani soils. J. Chem. Soc. Pak. 36: 1189-1195

[24] Khalid R, Mahmood T, Bibi R, Siddique M T, Alvi S and Naz S Y 2012 Distribution and indexation of plant available nutrients of rainfed calcareous soils of Pakistan. Soil Environ. 31(2): 146-151

[25] Latif R, Ali S and Hayat R 2008 Nitrogen fixation and yield of peanut affected by inorganic fertilizers, variety and inoculums interaction in rainfed areas of Punjab. Soil Environ. 27: 77-83

[26] Nemeth-Konda L, Füleky G, Morovjan G and Csokan P 2002 Sorption behaviour of acetochlor, atrazine, carbendazim, diazinon, imidacloprid and isoproturon on Hungarian agricultural soil. Chemosphere 48(5): 545-552 
[27] Banerjee K, Patil S H, Dasgupta S, Oulkar D P and Adsule P G 2008 Sorption of thiamethoxam in three Indian soils. $J$. Environ. Sci. Health B 43(2): 151-156

[28] Kandil M M, El-Aswad A F and Koskinen W C 2015 Sorption-desorption of imidacloprid onto a lacustrine Egyptian soil and its clay and humic acid fractions. J. Environ. Sci. Health B 50(7): 473-483. https://doi.org/10.1080/ 03601234.2015.1018758

[29] El Arfaoui A, Sayen S, Paris M, Keziou A, Couderchet M and Guillon E 2012 Is organic matter alone sufficient to predict isoproturon sorption in calcareous soils? Sci. Total Environ. 432: 251-256

[30] Kah M, Beulke S and Brown C D 2007 Factors influencing degradation of pesticides in soil. J. Agric. Food Chem. 55(11): 4487-4492. https://doi.org/10.1021/jf0635356

[31] Dankyi E, Gordon C, Carboo D, Apalangya V A and Fomsgaard I S 2018 Sorption and degradation of neonicotinoid insecticides in tropical soils. J. Environ. Sci. Health B 53(9): 587-594

[32] Ahmad K S 2017 Determination of Rimsulfuron sorption parameters in eight Pakistani soils. Agrochimica 61(2): $140-153$

[33] Ahmad K S 2017 Investigating the impact of soils physiochemical composition on chlorsulfuron pedospheric sorption. Studia Universitatis Babes-Bolyai Chemia 62(1): $165-174$

[34] Ahmad K S 2017 Pedospheric sorption investigation of sulfonyl urea herbicide Triasulfuron via regression correlation analysis in selected soils. S. Afr. J. Chem. 70(1): $163-170$
[35] Ahmad K S 2017 Green electrokinetic remediation of Thiabendazole adsorbed soils via mineralization. Agrochimica 61(3): 190-205

[36] Ahmad K S 2018 Evaluating the adsorption potential of alachlor and its subsequent removal from soils via activated carbon. Soil Sediment Contam. Int. J. 28: 249-266

[37] Rodríguez-Liébana J A, Mingorance M D and Peña A 2018 Thiacloprid adsorption and leaching in soil: effect of the composition of irrigation solutions. Sci. Total Environ. 610: 367-376

[38] Friedel J K, Langer T, Siebe C and Stahr K 2000 Effects of long-term waste water irrigation on soil organic matter, soil microbial biomass and its activities in central Mexico. Biol. Fertil. Soils 31: 414-421

[39] Fernández-Gálvez J, Gálvez A, Peña A and Mingorance M D 2012 Soil hydrophysical properties resulting from the interaction between organic amendments and water quality in soils from Southeastern Spain: a laboratory experiment. Agric. Water Manag. 104: 104-112

[40] Lado M, Bar-Tal A, Azenkot A, Assouline S, Ravina I, Erner Y, Fine P, Dasberg S and Ben-Hur M 2012 Changes in chemical properties of semiarid soils under long-term secondary treated wastewater irrigation. Soil Sci. Soc. Am. J. 76: 1358-1369

[41] Assouline S, Narkis K, Gherabli R and Sposito G 2016 Combined effect of sodicity and organic matter on soil properties under long-term irrigation with treated wastewater. Vadose Zone J. https://doi.org/10.2136/vzj2015.12.0158

[42] Singh N and Singh S B 2015 Adsorption and leaching behaviour of bispyribac-sodium in soils. Bull. Environ. Contam. Toxicol. 94(1): 125-128 